\title{
De effectiviteit van training in gespreksvaardigheden: zelfinstructie versus begeleide training
}

\author{
Winnende voordracht op het NVMO-congres 2001
}

\author{
J. Schönrock-Adema, K.I. van Oudenhoven-van der Zee
}

\section{Samenvatting}

Inleiding: Aan de Rijksuniversiteit Groningen worden trainingen in basisgespreksvaardigheden gegeven volgens de cumulatieve microtrainingsmethode. Hierbij wordt eerst één vaardigheid geleerd en in elke volgende training wordt een vaardigheid aan de reeds geleerde vaardigheden toegevoegd. Omdat het steeds moeilijker werd voldoende begeleiding te bieden is nagegaan of een zelfinstructietraining (ZI-training) met veel minder begeleiding even effectief is als een training die voornamelijk onder begeleiding plaatsvindt.

Ontwikkeling van de ZI-training: Bij de zelfinstructievorm werkten studenten zelfstandig met behulp van een werkboek. De begeleidingstijd werd zo met ongeveer $50 \%$ gereduceerd.

Methode: Het onderzoek werd uitgevoerd bij 193 tweedejaars studenten psychologie. In 1998 doorliepen 97 studenten de ZI-training en volgden 96 studenten de begeleide training. Het effect van de trainingen werd gemeten met behulp van twee soorten gedragstoetsen, namelijk rollenspeltoetsen en videotoetsen.

Resultaten: Uit de resultaten bleek dat beide trainingsvormen effectief waren. Bij de videotoets werden effectgroottes behaald van respectievelijk 1.44 en 1.63 voor begeleide training en ZItraining met werkboek en bij de rollenspeltoets effectgroottes van respectievelijk 2.11 en 2.30 .

Discussie: Het bleek mogelijk de begeleidingstijd bij een training in gespreksvaardigheden aanzienlijk te reduceren met behoud van leereffect. Hoewel de ZI-training minstens even effectief was als de begeleide training is het de vraag of beide trainingsvormen even effectief zijn voor iedere persoon. In vervolgonderzoek zou kunnen worden onderzocht of persoonlijkheid en leerstijl van invloed zijn op de effectiviteit van de trainingsvormen. (SchönrockAdema J, Oudenhoven-van der Zee KI van. De effectiviteit van training in gespreksvaardigheden: zelfinstructie versus begeleide training. Tijdschrift voor Medisch Onderwijs 2002;21(4):146-153.)

\section{Inleiding}

In de afgelopen jaren hebben diverse ontwikkelingen in de infrastructuur van het onderwijs, zoals verhogingen van collegegelden, studieduurverkorting, invoering van de tempobeurs en verhoging van de prestatienorm, de studielast voor studenten vergroot. De minister van onderwijs stelde daarom dat onderwijsinstellingen de kwaliteit en studeerbaarheid van het onderwijs moesten verbeteren om de studievoortgang van studenten te bespoedigen. Voor dit doel is door het Ministerie van Onderwijs, Cultuur en Wetenschappen in 1996 een fonds ingesteld ter verbe- tering van de kwaliteit en studeerbaarheid van studieprogramma's. Het huidige onderzoek vond plaats in het kader van een subsidie afkomstig uit dit Kwaliteit- en Studeerbaarheidsfonds. Met de bijdrage uit dit fonds werd een nieuwe onderwijsvorm ontwikkeld, namelijk een zelfinstructietraining (ZI-training) voor een basistraining in professionele gespreksvaardigheden in het verplichte doctoraaldeel van de opleiding Psychologie aan de Rijksuniversiteit Groningen. Bij deze nieuwe trainingsvorm gaan studenten zelfstandiger te werk. In het onderzoek is de effectiviteit van deze trainingsvorm vergeleken met 
die van de oorspronkelijke trainingsvorm, die voornamelijk onder begeleiding plaatsvond.

\section{Theoretische achtergronden en opbouw van de training gespreks- vaardigheden}

Een eerste uitgangspunt bij de training gespreksvoering is Bandura's theorie over sociaal leren. ${ }^{1}$ Volgens Bandura leren mensen van het zien van voorbeelden. Daarbij is het van belang dat het leerproces wordt gestuurd, bijvoorbeeld door observatieopdrachten. Daarnaast leert men door zelf te oefenen en in de derde plaats is bekrachtiging belangrijk: men leert alleen dan gedrag aan wanneer succesvolle uitvoering wordt bekrachtigd.

Bovenstaande principes zijn in belangrijke mate terug te vinden in de microtrainingsmethode die door Ivey is ontwikkeld. ${ }^{2} 3$ Kenmerkend voor Ivey's microtrainingsmethode is dat cursisten per keer één vaardigheid leren. Voorbeelden van vaardigheden zijn het stellen van open vragen en gevoel reflecteren. Deze vaardigheden worden volgens een vast stramien onderwezen. Zo voert men eerst een kort gesprek dat op video wordt opgenomen. Vervolgens krijgt de cursist theoretische instructie over de betreffende vaardigheid en videovoorbeelden van de toepassing van de vaardigheid. Daarna bekijkt de cursist het korte gesprek dat hij/zij zelf heeft gevoerd en bespreekt dit met de supervisor. Hierbij wordt alleen de centraal staande vaardigheid besproken en worden telkens de positieve aspecten uit het optreden van de cursist benadrukt. Ten slotte oefent de cursist de vaardigheid in rollenspelen, waarna hij/zij feedback krijgt. Deze methode blijkt over het algemeen een duidelijk effect te sorteren. ${ }^{4}$

Aan de methode die Ivey hanteert, kleven echter twee nadelen. ${ }^{5}$ Ten eerste oefent de student zonder de specifieke be- doelingen van het oefenen te kennen of voorbeelden te hebben gezien. Ten tweede worden telkens kleine gedragseenheden afzonderlijk geoefend zonder dat geïntegreerde toepassing in een complexere gesprekssituatie plaatsvindt. Lang en Van der Molen hebben daarom een methode ontwikkeld waarbij cursisten voorafgaand aan iedere trainingseenheid informatie krijgen over de bedoeling van het desbetreffende trainingsonderdeel. Daarnaast stelden ze een trainingsopbouw voor die, in aanvulling op de methode van Ivey, wordt gekenmerkt door een toenemende complexiteit van de oefenstof. Deze variant op de methode van Ivey wordt de cumulatieve microtrainingsmethode (CMT) genoemd. Men begint met het leren van één vaardigheid, en in elke volgende oefenronde wordt een vaardigheid toegevoegd. De trainingsopbouw die hieruit resulteert, ziet er als volgt uit:

a. Het bestuderen van theorie;

b. Het bekijken en bespreken van videovoorbeelden;

c. 'Droogzwemoefeningen' waarbij de vaardigheden geïsoleerd - dus niet in de context van een gesprek - worden geoefend;

d. Het oefenen in rollenspelen.

$\mathrm{Bij}$ het laatste onderdeel wordt telkens de nieuw geleerde vaardigheid toegevoegd aan reeds eerder geleerde vaardigheden.

\section{De mogelijkheden van zelfinstructie bij het verbeteren van de kwaliteit en studeerbaarheid van onderwijs}

Lange tijd is de basistraining gespreksvoering volgens bovengenoemde methode uitgevoerd. ${ }^{6}$ Hoewel de gebruikte methode effectief is, kleven er ook enkele bezwaren aan. ${ }^{6-10}$ Zo kan de begeleider bij de rollenspelen niet iedere cursist feedback geven, doordat de groep, die doorgaans uit negen tot twaalf studenten bestaat, bij dit onderdeel in drietallen wordt opge- 
splitst. De feedback van de begeleider tijdens de rollenspelen wordt door de studenten echter erg belangrijk gevonden. De relatief geringe begeleiding bij dit onderdeel wordt dan ook als een nadeel ervaren. Een tweede nadeel is dat practica waarin feedback door een trainer wordt gegeven, zeer veel begeleidingstijd vereisen, zeker wanneer er per jaar twee- tot driehonderd studenten moeten worden getraind. Daar komt nog bij dat het door inperking van de studietijd steeds moeilijker is geworden voldoende assistenten te vinden, die bereid zijn de taak van trainer op zich te nemen.

Een oplossing voor deze problemen leek de ontwikkeling van een ZI-programma voor bepaalde onderdelen van de training. Een eerste voordeel van zelfinstructie is dat een effectievere inzet van de docent mogelijk wordt bij die onderdelen waar begeleiding essentieel is. ${ }^{11}$ Een deel van de taken van de docent kan namelijk door het ZI-programma worden overgenomen. De lerende kan zo zelfstandig met de stof aan de slag, waardoor er voor de docent tijd vrijkomt voor specifieke persoonlijke begeleiding bij de onderdelen waar de directe inbreng en feedback van een deskundige gewenst zijn, bijvoorbeeld bij het oplossen van begripsproblemen of bij het geven van feedback op de uitvoering van complexe opdrachten. Door de trainingsgroepen daarnaast kleiner te maken, kan intensievere begeleiding gegeven worden bij die onderdelen waar begeleiding vereist is.

Ten tweede kan de verantwoordelijkheid voor het eigen leren de inzet van studenten en hun leerprestaties positief beïnvloeden. Zo is uit onderzoek in de arbeidsen organisatiepsychologie gebleken dat meer verantwoordelijkheid een positieve uitwerking kan hebben op prestaties van individuen. ${ }^{12}$ Uit onderzoek van Light blijkt dat zelfstandig werken in groepjes niet alleen een positieve invloed heeft op prestaties, maar vooral ook op de betrokkenheid van studenten bij wat ze leren en op hun motivatie. ${ }^{13}$

\section{De ontwikkeling van de Zl-training gespreksvoering}

Voor alle onderdelen, behalve de rollenspelen, zijn ZI-onderdelen ontwikkeld. Bij de rollenspelen werd inbreng van een docent zo essentieel geacht, dat daar geen ZI-onderdeel voor werd ontwikkeld. Studenten doorliepen de ZI-onderdelen zelfstandig. Om te zorgen dat de bijeenkomst gestructureerd verliep, nam telkens één student de taak van voorzitter op zich. Om de bijeenkomsten effectief te houden zijn de groepjes kleiner gemaakt, zodat ze uit maximaal zes personen bestonden. In totaal werd de docenteninzet met de helft teruggebracht.

\section{Onderzoeksvragen}

Het doel van het onderzoek was na te gaan of de begeleide en de ZI-training effectief waren, dus of studenten na de training gespreksvaardiger waren dan ervoor. De verwachting was dat ze effectief waren. Exploratief werd daarnaast onderzocht of beide trainingsvormen van elkaar verschilden in effectiviteit.

\section{Methode}

\section{Proefpersonen}

Het onderzoek werd in 1998 uitgevoerd onder 193 studenten Psychologie aan de Rijksuniversiteit Groningen, die een cursus gespreksvoering volgden. De cursus behoorde tot het verplichte doctoraaldeel van de studie. Het onderzoek werd gepresenteerd als onderdeel van de cursus. Studenten werden willekeurig toegewezen aan één van de onderwijsvormen. Van de 193 studenten doorliepen 97 de traditionele training (TT) en 96 de ZI-training. Omdat het nodig werd geacht dat 
studenten over bepaalde voorkennis beschikten voordat ze de training volgden, bestudeerden ze voor aanvang het boek 'Psychologische gespreksvoering' van Lang en Van der Molen en werden ze over deze literatuur getoetst. ${ }^{14}$

\section{Instrumenten}

\section{Rollenspeltoets}

Van de rollenspeltoets werden twee vergelijkbare versies geconstrueerd (versie A en B), waarvoor vooraf concrete gedragsdimensies zijn opgesteld met als doel de scoringsmethoden zo objectief mogelijk te maken. In beide versies van de toets dient de student een eerste probleemverhelderend gesprek van maximaal twintig minuten te voeren met een cliënt. Een getrainde acteur voert de cliëntenrol uit volgens een gestandaardiseerd script. Het script bevat een aantal verschillende situaties waarin de cliënt specifieke vaardigheden kan toepassen. De student werd op houding en toepassing van vaardigheden onafhankelijk beoordeeld door twee beoordelaars, die vooraf intensief waren getraind in het gebruik van de beoordelingsschalen. De beoordeling was gericht op elf essentiële elementen of vaardigheden die deel uitmaken van het hulpverleningsgesprek, waarbij gebruik werd gemaakt van een vijfpuntsschaal (1=slecht; $5=$ zeer goed). De eindscore was de gemiddelde score over de items. Een standaardbeoordelingsformulier werd ontwikkeld om de scoring te vergemakkelijken.

\section{Videotoets}

Van de videotoets werden eveneens twee vergelijkbare versies (versie A en B) ontwikkeld. Elke versie bestaat uit dertig videofragmenten, waarbij een studentacteur de rol van cliënt op zich neemt, recht in de camera kijkt en over een probleem of gebeurtenis vertelt. De student wordt gevraagd om als gespreksleider te reageren en een adequate reactie te formuleren. Welke vaardigheid de student daarbij dient toe te passen is aangegeven op een testformulier dat voorafgaand aan de toets is uitgereikt. De student noteert het antwoord op dit formulier. Om beoordelingsregels te construeren, werd voor elk item een aantal goede en foute voorbeeldantwoorden opgesteld en deze werden aan vier experts voorgelegd. Op grond van hun indeling, die tot stand kwam aan de hand van algemene regels voor het beoordelen van vaardigheden, werd de uiteindelijke antwoordsleutel vastgesteld. ${ }^{14}$ Voor ieder antwoord kreeg men 2 punten (goed), 1 punt (matig) of 0 punten (fout). Op basis van een pilotstudie onder achttien studenten werden twee redelijk betrouwbare versies geconstrueerd (alfa was .76 voor versie A en .73 voor versie $B$ ) van vergelijkbare moeilijkheidsgraad $(\mathrm{t}(17)=.20$; niet significant).

\section{Onderzoeksontwerp en procedure}

Het onderzoek was opgezet volgens een pretest-posttest design (tabel 1). Voor de training werden de studenten getoetst met beide toetsen, waarbij steeds de helft van de studenten getoetst werd met behulp van versie A en de andere helft met versie B. De versies werden willekeurig aan studenten toegewezen. Na de training kreeg de student de andere versie van de toets. Van de studenten werd verwacht dat ze voor aanvang van de training de theorie over gespreksvoering zo goed hadden bestudeerd dat ze een voldoende op het literatuurtentamen konden halen. Het literatuurtentamen en de voormeting met de videotoets vonden plaats op de dag voor aanvang van de training. De nameting met de videotoets vond plaats op de dag na de training. In verband met logistieke problemen was het niet mogelijk de rollenspeltoetsen op dezelfde momenten voor en na 
Tabel 1. Overzicht pretest-posttest design.

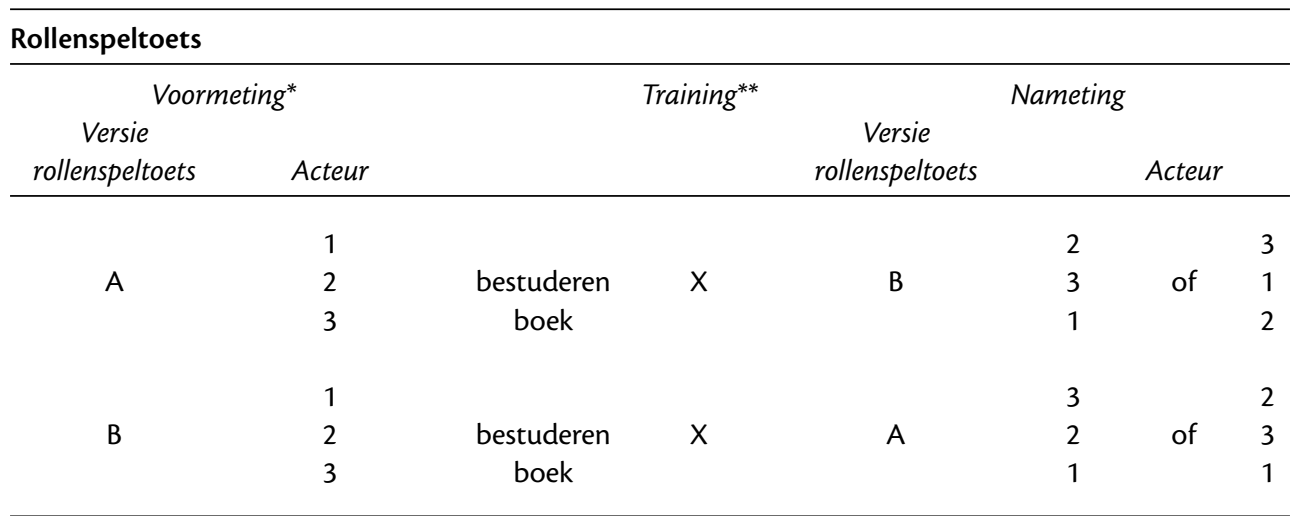

\section{Videotoets}

\begin{tabular}{ccc}
\hline $\begin{array}{c}\text { Voormeting } \\
\text { Versie videotoets }\end{array}$ & Training** $^{* *}$ & $\begin{array}{c}\text { Nameting } \\
\text { *** } \\
\text { Versie videotoets }\end{array}$ \\
\hline
\end{tabular}

bestuderen boek

$\begin{array}{lll}\text { A } & \text { X } & B \\ B & X & A\end{array}$

* Door logistieke problemen was het niet mogelijk de voormeting van de rollenspeltoets af te nemen nadat studenten het boek hadden bestudeerd.

** Zelfinstructie (ZI) of traditionele training met begeleiding (TT).

*** Telde mee in het eindcijfer voor de cursus.

de training af te nemen. De periode tussen de voormeting van de rollenspeltoets en het begin van de training varieerde van twee tot vijf maanden. Bij alle studenten werd de nameting van de rollenspeltoets binnen een week na de training verricht.

\section{Resultaten}

\section{Rollenspeltoets}

\section{Interne consistentie}

De interbeoordelaarsbetrouwbaarheden waren zeer hoog $(\geq .97)$. Als maat voor de interne consistenties van beide toetsversies werd Cronbachs alfa berekend. $\mathrm{Na}$ verwijdering van één item met een negatieve item-totaalcorrelatie bestond de schaal uit tien items. Uit tabel 2 blijkt dat de interne consistentie van beide toetsversies redelijk hoog tot hoog was.
Trainingseffect

Uit de resultaten die met behulp van multilevel-analyses werden verkregen, bleek dat beide trainingsvormen zeer effectief waren: het leereffect was significant voor zowel ZI als TT $(\mathrm{p}<.001)$. Voor de overzichtelijkheid en eenvoud wordt hier volstaan met het rapporteren van effect-

Tabel 2. Interne consistenties van de rollenspeltoets na correctie.

\begin{tabular}{lcccc}
\hline Meetmoment & Versie & Alfa & M & SD \\
\hline Voor- en & A & .86 & 2.53 & .67 \\
nameting & B & .87 & 2.52 & .69 \\
& & & & \\
Voormeting & $\mathrm{A}$ & .76 & 2.08 & .46 \\
& $\mathrm{~B}$ & .77 & 1.97 & .45 \\
& & & & \\
Nameting & $\mathrm{A}$ & .76 & 3.04 & .49 \\
& $\mathrm{~B}$ & .68 & 3.05 & .39 \\
\hline
\end{tabular}


Tabel 3. Effectgroottes behaald met de rollenspeltoets.

\begin{tabular}{lccccccc}
\hline & \multicolumn{2}{l}{ Voormeting } & \multicolumn{2}{c}{ Nameting } & \multicolumn{3}{c}{ Vooruitgang } \\
\hline & M & SD & M & SD & M & SD & $\begin{array}{c}\text { Effect- } \\
\text { grootte }\end{array}$ \\
\hline $\mathrm{TT}^{*}$ & 2.00 & .47 & 2.99 & .46 & .99 & .51 & 2.11 \\
$\mathrm{Zl}^{* *}$ & 2.05 & .45 & 3.08 & .42 & 1.03 & .50 & 2.29 \\
\hline
\end{tabular}

* $\mathrm{TT}=$ traditionele training

** $\mathrm{ZI}=$ zelfinstructie

groottes (tabel 3). Een effectgrootte van .8 wordt als een groot effect beschouwd. 1516 De effecten die gemeten werden met behulp van de rollenspeltoets bedroegen 2.11 en 2.29. Beide trainingsvormen waren even effectief.

\section{Videotoets}

Betrouwbaarheid en interne consistentie Om de mate van overeenstemming tussen de beoordelaars te bepalen is Pearsons product-moment-correlatiecoëfficiënt (pmcc) berekend over de totaalscores van de proefpersonen (tabel 4). Voor beide versies van de videotoets en beide meetmomenten was de interbeoordelaarsbetrouwbaarheid redelijk hoog.

Cronbachs alfa werd berekend nadat de itemscores waren gemiddeld over beide beoordelaars. Na verwijdering van onbetrouwbare toetsitems bestonden beide toetsversies uit 28 items met een maximaal mogelijke score van 56 punten (maximaal twee punten per item). De interne consistenties varieerden van .67 voor de nameting met versie A tot .87 voor voor- en nameting met versie A (tabel 5). Opvallend is dat de interne consistentie bij de nameting iets lager was dan bij de voormeting. Mogelijk is restriction of range de oorzaak van de lagere alfa's bij de nameting. De gemiddelde scores op de toetsversies duiden op een verschil in moeilijkheidsgraad tussen beide versies:
Tabel 4. Interbeoordelaarsbetrouwbaarheden videotoets.

\begin{tabular}{lccc}
\hline & \multicolumn{3}{c}{$\begin{array}{c}\text { Pearsons pmcc } \\
\text { Versie }\end{array}$} \\
\cline { 2 - 4 } Meetmoment & $\mathrm{A}$ & $\mathrm{B}$ & A en B \\
\hline voor- en nameting & .89 & .85 & .87 \\
voormeting & .84 & .81 & .83 \\
nameting & .72 & .75 & .74 \\
\hline
\end{tabular}

Tabel 5. Interne consistenties van de videotoets na correctie.

\begin{tabular}{lcccc}
\hline Meetmoment & Versie & Alfa & M & SD \\
\hline Voor- en & A & .87 & 24.02 & 9.27 \\
nameting & B & .81 & 26.05 & 7.65 \\
& & & & \\
Voormeting & A & .80 & 17.11 & 7.21 \\
& B & .72 & 21.76 & 6.34 \\
& & & & \\
Nameting & A & .67 & 30.31 & 5.80 \\
& B & .71 & 30.77 & 6.01 \\
\hline
\end{tabular}

bij de voormeting en bij voor- en nameting samen worden op versie A gemiddeld lagere scores behaald dan op versie B.

\section{Trainingseffect}

Uit de resultaten van de multilevel-analyses bleek inderdaad dat versie A van de videotoets bij de voormeting iets moeilijker was dan versie B. Daarom werd in de vervolganalyses gecorrigeerd voor toetsversie. Beide trainingsvormen bleken effectief $(\mathrm{p}<.001)$. Om dezelfde reden als 
Tabel 6. Effectgroottes behaald met de videotoets.

\begin{tabular}{lccccccc}
\hline & \multicolumn{2}{c}{ Voormeting } & \multicolumn{2}{c}{ Nameting } & & Vooruitgang \\
\hline & M & SD & M & SD & M & SD & $\begin{array}{c}\text { Effect- } \\
\text { grootte }\end{array}$ \\
\hline TT & 19.31 & 7.27 & 29.85 & 6.02 & 10.54 & 7.46 & 1.45 \\
ZI & 19.77 & 7.04 & 31.21 & 5.71 & 11.43 & 7.39 & 1.62 \\
\hline
\end{tabular}

hiervoor worden hier alleen effectgroottes gerapporteerd (tabel 6). De effectgroottes bij deze toetsvorm bedroegen 1.45 en 1.62. Het effect van de ZI-training was minstens even groot als dat van de TT en op het oog zelfs iets groter, maar uit de multilevel-analyses bleek dat het verschil tussen de leereffecten van beide trainingsvormen niet significant was.

\section{Discussie}

Zoals verwacht, waren beide trainingsvormen effectief voor het aanleren van gespreksvaardigheden. Er was geen verschil in effectiviteit tussen beide trainingsvormen. Het is dus bij training in basisgespreksvaardigheden mogelijk een even groot leereffect te realiseren met de helft van de oorspronkelijke begeleiding. Daarbij moet wel in het oog worden gehouden dat bij de ZI-training duidelijk is gekozen voor begeleiding bij die onderdelen waar dat essentieel werd geacht en dat de huidige bevindingen niet inhouden dat de begeleiding zonder problemen verder kan worden gereduceerd.

Zoals eerder werd aangegeven, vraagt zelfinstructie-onderwijs meer zelfstandigheid en een actievere inzet van de student, hetgeen het leereffect positief kan beïnvloeden. ${ }^{12}$ Naast deze mogelijke positieve invloed op het leereffect kan echter ook de uitwerking van het onderwijsmateriaal van invloed zijn geweest op het trainingseffect: het ontwikkelen van een zelfinstructieprogramma vereist een grote zorgvuldigheid en explicitering bij de samenstelling van het onderwijsmateriaal. Omdat de docent niet steeds aanwezig is, moet het materiaal zoveel informatie bevatten dat de student ook in afwezigheid van de docent het programma kan doorlopen. Het is mogelijk dat hierdoor een kwaliteitsverbetering is opgetreden die losstaat van de onderwijsmethode.

\section{Aanbevelingen voor vervolgonderzoek}

Alhoewel zelfinstructie in dit onderzoek gemiddeld genomen even effectief bleek als begeleide training, is het de vraag of beide trainingsvormen voor elke student even geschikt zijn. Het kan zijn dat de ene trainingsvorm geschikter is voor personen met bepaalde eigenschappen of leerstijlen dan de andere of dat de motivatie of voorkeur voor een trainingsvorm het leereffect beïnvloedt. Het verdient daarom aanbeveling om vervolgonderzoek uit te voeren naar de invloed van deze variabelen op het leereffect.

In de tweede plaats verdient het aanbeveling te onderzoeken of de huidige bevindingen wat betreft de effectiviteit van zelfinstructie ook generaliseerbaar zijn naar trainingen waarin complexere vaardigheden worden aangeleerd of naar meer theoretisch onderwijs. Oefeningen die betrekking hebben op complexere vaardigheden vereisen vermoedelijk complexere feedback. Het is de vraag of de docenteninzet in zo'n geval evenzeer kan worden gereduceerd als in het onderhavige onderzoek. 


\section{Literatuur}

1. Bandura A. Social foundations of thought and action. A social cognitive theory. Englewood Cliffs, New Jersey: Prentice Hall; 1986.

2. Ivey AE. Microcounseling. Innovations in interviewing training. Springfield: Charles C. Thomas; 1971.

3. Ivey AE, Authier J. Microcounseling. Innovations in interviewing, counseling, psychotherapy, and psychoeducation. Springfield: Charles C. Thomas; 1978.

4. Baker SB, Daniels TG. Integrating research in the microcounseling program: a meta-analysis. Journal of Counseling Psychology 1989;36:213-22.

5. Lang G, Molen HT van der. Methodiek van gesprekstraining. Baarn: Nelissen; 1992.

6. Smit GN. De beoordeling van professionele gespreksvaardigheden. Constructie en evaluatie van rollenspel-, video- \& schriftelijke toetsen [dissertatie]. Baarn: Nelissen; 1995.

7. Molen HT van der, Smit GN, Hommes MA, Lang G. Two decades of cumulative microtraining in the Netherlands: an overview. Educational Research and Evaluation 1995;1:347-78.

8. Smit GN, Molen HT van der. Development and evaluation of a video test for the assessment of interviewing skills. Journal of Cancer Education 1995;10:195-9.

9. Smit GN, Molen HT van der. Three methods for the assessment of communication skills. The British Journal of Educational Psychology 1996;66:543-56

10. Bögels SM, Kreutzkamp R. Effecten van een training in basale gespreksvaardigheden. Tijdschrift voor Onderwijsresearch 1990;15:201-14.

11. Zee KI van der, Lang G, Adema J. Het gebruik van multimediale computersystemen binnen trainingen in professionele gespreksvaardigheden. In: Mirande M, Riemersma J, Veen W, redactie. Hoger Onderwijs Reeks. De digitale leeromgeving. Groningen: Wolters-Noordhoff; 1997. p. 273-282.

12. Eijnatten FM van. Ontwikkelingen in de sociotechniek. In: Drenth PJD, Thierry Hk, Wolff CJ de, redactie. Nieuw handboek arbeids- en organisatiepsychologie. Houten: Bohn Stafleu Van Loghum; 1992.

13. Light RJ. The Harvard Assessment Seminars. Explorations with students and faculty about teaching, learning and student life. First report. Cambridge, Massachusetts: Harvard University; 1990.

14. Lang G, Molen HT van der. Psychologische gespreksvoering. Een basis voor hulpverlening. Baarn: Nelissen; 1991, 1998.

15. Cohen J. Statistical power analysis for the behavioral sciences. rev. ed. New York: Academic press; 1979.

16. Glass GV. Primary, secondary, and meta-analysis of research. Educational Researcher 1976;5:3-8.

\section{De auteurs:}

Drs. Johanna Schönrock-Adema, consulent Onderwijsinstituut, Faculteit der Medische Wetenschappen, Rijksuniversiteit Groningen.

Prof. dr. Karen I. van Oudenhoven-van der Zee, hoogleraar Organisatie Psychologie, Rijksuniversiteit Groningen.

\section{Correspondentieadres:}

Johanna Schönrock-Adema, Faculteit der Medische Wetenschappen, Onderwijsinstituut, A. Deusinglaan 1, 9713 AV Groningen, Tel: 050-3638378, fax: 050-3633865, J.Schoenrock-Adema@med.rug.nl.

\section{Summary}

Introduction: At the University of Groningen basic counselling skills are taught using the cumulative microcounselling method. One skill is learned in the first session and in every subsequent training session one skill is added. Because of increasing difficulty in recruiting sufficient numbers of supervisors a study was performed to determine the learning effectiveness of self-instruction with reduced supervision versus that of supervised training.

Development of self-instruction: In self-instruction students learn independently using a workbook. Supervision was reduced by $50 \%$ in comparison with supervised training.

Method: In 1998 a study was performed among 193 second-year psychology undergraduates: 97 students participated in self-instruction training and 96 students attended supervised training. The learning effects were measured using two types of behaviour tests, namely role-playing tests and video tests.

Results: Both training modes proved to be effective. The video test yielded effect sizes of 1.44 and 1.63 for supervised training and self-instruction, respectively and the role-playing test yielded effect sizes of 2.11 and 2.30, respectively.

Discussion: It appears to be feasible to reduce supervision of training in basic counselling skills by 50\% while retaining learning effectiveness. Although self-instruction proved to be as effective as supervised training, it remains to be seen whether the effects of both training modes are similar for all students. Future investigations should address the influence of personality and learning style on the effectiveness of self-instruction and supervised traininng. (Schönrock-Adema J, Van Oudenhoven-van der Zee KI. The effectiveness of training in basic counselling skills: selfinstruction versus supervised training. Dutch Journal of Medical Education 2002;21(4):146-153.) 